\title{
Distal myopathy with posterior leg and anterior hand involvement
}

INSERM

\section{Source}

INSERM. (1999). Orphanet: an online rare disease and orphan drug data base. Distal myopathy with posterior leg and anterior hand involvement. ORPHA:63273

Distal myopathy with posterior leg and anterior hand involvement, also named distal ABD-filaminopathy, is a neuromuscular disease characterized by a progressive symmetric muscle weakness of anterior upper and posterior lower limbs. 